REVISTA DE GEOCIÊNCIAS DO NORDESTE

Northeast Geosciences Journal

v. $7, \mathrm{n}^{\circ} 2(2021)$

ISSN: $2447-3359$

https://doi.org/10.21680/2447-3359.2021v7n2ID20625

\title{
SECAS, INUNDAÇÕES E DESASTRES SOCIONATURAIS ASSOCIADOS: UMA ANÁLISE ESTATÍSTICA DE PERÍODOS SECOS E CHUVOSOS EM HIDROLÂNDIA-CE
}

\section{Francisco Railson da Silva Costa ${ }^{1}$; Jander Barbosa Monteiro ${ }^{2}$}

${ }^{1}$ Bacharel em Geografia, Secretaria de Desenvolvimento Agrário e Recursos Hídricos, Prefeitura Municipal de Hidrolândia (PMH), Hidrolândia/CE, Brasil.

ORCID: $\underline{\text { https://orcid.org/0000-0002-8299-9385 }}$

Email: railson.costa00@gmail.com

${ }^{2}$ Doutor em Geografia, Professor Adjunto do Curso de Geografia e Mestrado Acadêmico em Geografia, Universidade Estadual Vale do Acaraú (UVA), Sobral/CE, Brasil.

ORCID: https://orcid.org/0000-0003-0086-6923

Email: jander_monteiro@uvanet.br

\section{Resumo}

O município de Hidrolândia, inserido no Semiárido Nordestino Brasileiro (NEB), apresenta períodos em que podem ocorrer eventuais desastres socionaturais associados à ausência de chuva ou excesso da mesma, acarretando em estiagens e inundações. O artigo teve como objetivo analisar os desastres socionaturais associados às estiagens e inundações no município de Hidrolândia no período de 1989-2018. Inicialmente, foram obtidos dados pluviométricos na Fundação Cearense de Meteorologia e Recursos Hídricos - FUNCEME para aplicação da técnica dos quantis, através do método de Pinkayan (1966). Em seguida, identificaram-se situações de desastres associados aos períodos secos e chuvosos no município, a partir de análises nos documentos presentes no Banco de dados do Sistema Integrado de Informações sobre Desastres (S2iD), os quais apresentam informações sobre número de atingidos, decretos de Situação de Emergência (SE), Estado de Calamidade Pública (ECP) e reconhecimento de desastres socionaturais. De forma concomitante, foram identificados os sistemas atmosféricos e teleconexões que interferiram nos acumulados superiores e inferiores. A Zona de Convergência Intertropical - ZCIT foi o sistema atmosférico que mais influenciou na formação de chuvas. Já o El Niño contribuiu consideravelmente para a ocorrência de secas. Ao menos doze situações de desastre foram verificadas em Hidrolândia na série histórica analisada.
Palavras-chave: Hidrolândia; Desastres Socionaturais; Quantis.

DROUGHTS, FLOODS AND SOCIAL-NATURAL DISASTERS ASSOCIATED: A STATISTICAL ANALYSIS OF DRY AND RAINY PERIODS IN HIDROLÂNDIA-CE

\section{Abstract}

In the municipality of Hidrolandia in inserted in the Brazilian Northeastern Semi-Arid it presents periods in which possible socio-natural disasters can occur associated with the absence of rain or excessive rain, resulting in droughts and floods. The article aimed to analyze the socio-natural disasters associated with droughts and floods in the municipality of Hidrolândia in the period 1989-2018. Initially, rainfall data were obtained from the Cearense Foundation of Meteorology and Water Resources FUNCEME for application of the quantile technique, using the method of Pinkayan (1966). Then, disaster situations associated with dry and rainy periods in the municipality were identified, based on analyzes in the documents present in the Database of the Integrated Disaster Information System (S2iD), which present information on the number of people affected, decrees Emergency Situation (SE), State of Public Calamity (ECP) and recognition of socio-natural disasters. Concomitantly, atmospheric systems and teleconnections that interfered in the upper and lower accumulations were identified. The Intertropical Convergence Zone - ZCIT was the atmospheric system that most influenced the formation of rains. El Niño contributed considerably to the occurrence of droughts. At least twelve disaster situations were verified in Hidrolândia in the historical series analyzed.

Keywords: Hidrolândia; Socionatural Disasters; Quantile.

\section{SEQUIAS, INUNDACIONES Y DESASTRES SOCIONATURALES ASOCIADOS: UN ANÁLISIS ESTADÍSTICO DE PERÍODOS SECOS Y LLUVIOSOS EN HIDROLÂNDIA-CE}

\section{Resumen}

El municipio de Hidrolândia, inserido en el Nordeste Semiárido Brasileño (NEB), tiene períodos en que se puede ocurrir posibles desastres socionaturales asociados con la escasez de lluvia o 
lluvia excesiva, resultando en sequías e inundaciones. El artículo tuvo como objetivo analizar los desastres socionaturales asociados con sequías e inundaciones en el municipio de Hidrolândia en el período 1989-2018. Inicialmente, los datos de lluvia se obtuvieron de la Fundación Cearense de Meteorología y Recursos Hídricos (FUNCEME) para la aplicación de la técnica de los quantiles, utilizando el método de Pinkayan (1966). Luego, se identificaron situaciones de desastre asociadas con períodos secos y lluviosos en el municipio, con base en análisis en los documentos presentes en la Base de Datos del Sistema Integrado de Información de Desastres (S2iD), que presentan informaciones sobre el número de personas afectadas, Situaciones de Emergencia (SE), Estado de Calamidad Pública (ECP) y reconocimiento de desastres socionaturales. Concomitantemente, se identificaron sistemas atmosféricos y teleconexiones que interfirieron en los acumulados de lluvia superior e inferior. La Zona de Convergencia Intertropical - ZCIT fue el sistema atmosférico que más influyó en la formación de lluvias. Mientras que El Niño contribuyó considerablemente para la ocurrencia de sequías. Se verificaron al menos doce situaciones de desastre en Hidrolândia en la serie histórica analizada.

Palabras-clave: Hidrolândia; Desastres Socionaturales; Quantiles.

\section{INTRODUÇÃO}

Os desastres socionaturais estão relacionados à própria evolução da sociedade e a condição em que a mesma se amolda da natureza e usufrui dos seus recursos. Em tempos pretéritos, mesmo com a presença de aglomerações humanas que não eram tão significativas como as que se observam na atualidade, já ocorriam desastres. No entanto, nos últimos decênios, a apreensão com os impactos associados aos desastres socionaturais foram ampliadas de forma notável, tomando proporções gradativamente mais alarmantes.

Desse modo, esse alarmismo pode estar associado aos danos e prejuízos sociais, ambientais e econômicos que os desastres socionaturais têm apresentado nos últimos decênios, ocasionando sucessivos impactos e danos em grandes proporções à muitas sociedades contemporâneas. Tal perspectiva deve-se, particularmente, ao crescimento populacional, a ocupação desordenada e ao intenso processo de urbanização e industrialização (KOBIYAMA et. al., 2006).

No Brasil, os desastres socionaturais mais comuns são as inundações, a seca, a erosão e os escorregamentos ou deslizamentos de terra. Consequentemente, eles são os principais responsáveis por uma quantidade elevada de perdas humanas e materiais todos os anos. Por esse motivo, os processos estão fortemente interligados à degradação de áreas instáveis, potencializado pelo desmatamento e ocupação irregular (MAFFRA; MAZZOLA, 2007).

No Nordeste brasileiro, região com maior ocorrência de desastres socionaturais (com cerca de $40 \%$ dos eventos do país), aponta-se uma tendência semelhante ao cenário nacional, em outras palavras, uma maior ocorrência de desastres associados à estiagem/seca (apresentando $78 \%$ dos eventos na região) e à inundações (em torno de $21 \%$ dos eventos na região) (CEPED/UFSC, 2012; BRASIL, 2014, 2016).
Neste âmbito se insere o Estado do Ceará, localizado na porção mais setentrional da região Nordeste, onde as estiagens e as inundações são os desastres socionaturais que mais verificamse, isto é, estando correlacionados aos impactos oriundos das precipitações, na ocorrência ou não destas. Assim, os estudos associados aos impactos oriundos de precipitações elevadas ou da escassez de chuvas obtêm, cada vez mais, um importante significado no território brasileiro, assim como no Estado do Ceará.

Nesse contexto, o município de Hidrolândia-CE, assim como a maioria dos municípios interioranos que compõe o Semiárido Nordestino Brasileiro (NEB), apresenta períodos secos e chuvosos em que podem ocorrer eventuais desastres socionaturais, associados à ausência de chuva ou excesso da mesma, acarretando em estiagens e inundações.

A fim de considerar o comportamento da chuva a partir da observação de episódios extremos (estiagens e inundações) no município de Hidrolândia, bem como os impactos associados, este artigo objetivou analisar os desastres socionaturais associados às estiagens e inundações no município de Hidrolândia-CE, no período de 1989-2018.

Como objetivos específicos, procurou realizar uma análise estatística para identificar períodos secos e chuvosos na série histórica em análise por meio da técnica dos quantis; identificar, de forma operacional, possíveis situações de desastre no município de Hidrolândia, além de analisar e apontar quais os principais sistemas atmosféricos e teleconexões que influenciaram na ocorrência de anos secos e chuvosos no município.

Localizado a $227 \mathrm{~km}$ da capital do Estado (Fortaleza), o município de Hidrolândia está posicionado na região Noroeste do Estado do Ceará (Figura 1). Apresenta um clima Tropical Quente Semiárido, com temperaturas médias anuais em torno de $26^{\circ}$ a $28^{\circ} \mathrm{C}$, apresentando uma média pluviométrica de $800 \mathrm{~mm}$ anuais, com atividades pluviométricas mais significativas no quadrimestre fevereiro-maio. Com uma vegetação predominante de Caatinga Arbustiva Aberta e Floresta Caducifólia Espinhosa, bastante espessa no território, o município praticamente encontrase inserido na unidade geoambiental da Depressão Sertaneja e na Bacia Hidrográfica do rio Acaraú (SOUZA, 2007).

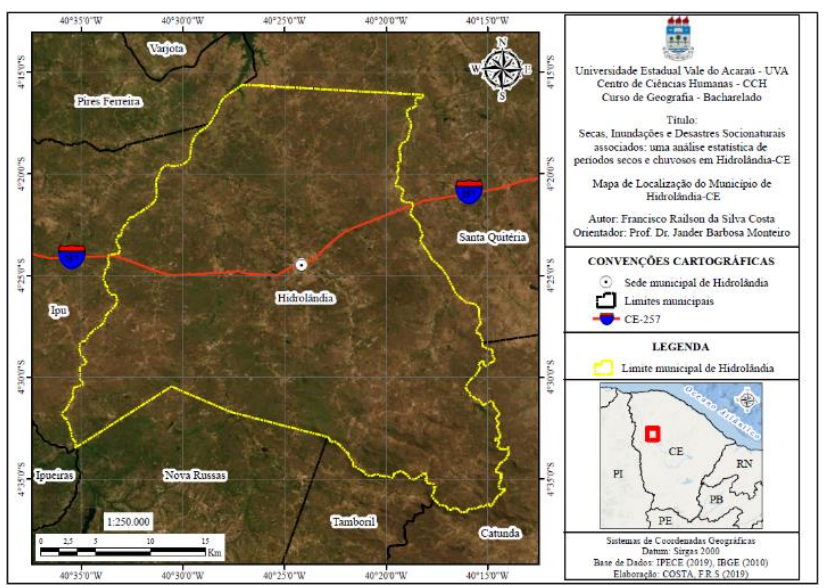

Figura 1 - Mapa de Localização do município de HidrolândiaCE.. Fonte: autor (2019). 
Esta investigação possibilitou, além de uma análise em termos estatísticos sobre o comportamento da chuva no município, a identificação de situações de desastres socionaturais, informações estas que podem ser utilizadas em investigações futuras, bem como para conhecimento do município, sobretudo na gestão pública, no que se refere à tomada de decisões que propiciem medidas preventivas e mitigadoras.

\section{O DESASTRE SOCIONATURAL EM PERSPECTIVA CONCEITUAL.}

Os desastres podem ser compreendidos como a consequência de eventos adversos que ocasionam impactos na sociedade e são diferenciados em função de sua origem, ou seja, da natureza do fenômeno que o provoca (TOBIN; MONTZ, 1997).

Na perspectiva de Romero e Maskrey (1993), um desastre natural pode ser compreendido a partir do paralelismo existente entre um fenômeno natural perigoso (chuva torrencial, por exemplo), condições socioeconômicas e físicas vulneravéis.

No entanto, há que se destacar que, em muitos casos, seja pela mídia ou pelo senso comum, o que por vezes ocorre é uma interpretação equivocada de que o desastre 'natural' advém de forças naturais ou sobrenaturais poderosas, como se a natureza ou um ser supremo (conexão com uma divindade) agissem sobre a sociedade por desforra.

Mas o pensamento natural ou sobrenatural foi, aos poucos, cedendo lugar a um pensamento mais social e integral dos desastres naturais. $\mathrm{O}$ desastre natural deixou de ser visto como uma expressão que se aproxima do conceito de fenômeno natural e aspectos relacionados à forma como as sociedades se organizam e contribuem para o incremento dos desastres passaram a ser considerados. Ora, a própria vulnerabilidade torna-se um componente importante nesta equação complexa. Assim, alguns autores passaram até a utilizar um outra terminologia: desastre socionatural (MONTEIRO; ZANELLA, 2019).

\section{O BINÔMIO SECA-ENCHENTE NO ESTADO DO CEARÁ E NORDESTE BRASILEIRO.}

Falar do Nordeste brasileiro em uma perspectiva climática pode significar, a princípio e a grosso modo, mencionar as elevadas temperaturas e escassez de chuva. No entanto, nem sempre é essa "imagem" que observamos quando analisamos o comportamento da chuva nesta região, a qual é concentrada em curto período (poucos meses) e mal distribuída no tempo e espaço.

Ademais, para compreender a seca em sua essência, faz-se necessário entender também a própria ocupação e o desenvolvimento econômico da região. Ou seja, não trata-se apenas de escassez de chuva (MONTEIRO, 2016). Existe um forte componente social que deve ser considerado, uma vez que a vulnerabilidade constitui-se como um elemento preponderante na análise. Inclusive, o próprio papel do estado, em especial na implementação de medidas preventivas e políticas públicas representa um verdadeiro ponto de inflexão, contribuindo para minimizar os danos. Do contrário, se ocorre a negligência por parte do poder público, os efeitos associados à ocorrência de secas e inundações acabam por apresentar impactos ainda mais significativos para as populações vulneráveis e desassistidas.
Os relatos de secas importantes permeiam os documentos históricos (ALVES, 2003) e até a literatura que traz como pano de fundo a região Nordeste. Secas como a de 1777-78, 1790-93, 1915, entre outras que ocorreram em períodos mais recentes, como as secas de 1983, 1993, 2012-2016 etc. trazem à tona uma situação recorrente que repercute em perdas, danos e até na adoção de estratégias por parte do poder público (geralmente após grandes secas) e comunidades no intuito de adaptar-se, de conviver com essa situação adversa.

O Estado do Ceará, que possui a grande maioria de seu terriório encravado em ambiente semiárido, vivencia de forma recorrente a seca. No entanto, entre um episódio e outro de seca, as fortes chuvas evidenciam um curioso contraste no Estado, mais uma vez desencadeando danos humanos e materiais vultosos, principalmente em áreas densamente urbanizadas.

Enquanto a mídia impressa proporcionava destaque de capa nos jornais de circulação local por conta dos danos associados às chuvas torrenciais de 1974, o país assistiu perplexo às manchetes televisivas em 2009 que apresentavam uma cenário caótico em muitos municípios cearenses, em virtude das fortes chuvas.

Ainda que o povo nordestino aguarde ansiosamente a temporada de chuvas, tais eventos extremos, quando ocorrem, desencadeiam desastres de grandes proporções. E assim o binômio seca-enchente torna-se tão marcante nessa região e necessário de ser compreendido em sua essência.

Esse comportamento da chuva é, em grande parte, fruto da flutuação e intensidade do principal sistema atmosférico que ocasiona chuvas importantes na porção setentrional do Nordeste Brasileiro: a Zona de Convergência Intertropical - ZCIT, principalmente no quadrimestre chuvoso fevereiro-maio para o Estado do Ceará. Ademais, outros mecanismos como o El Niño Oscilação Sul - ENOS e o Dipolo de TSM do Atlântico Intertropical são importantes preditores para definir o quão abundante serão as chuvas no período (FERREIRA; MELLO, 2005; XAVIER, 2001; MONTEIRO, 2016).

Alguns sistemas atmosféricos também podem contribuir com acumulados importantes e até atuar conjuntamente com a ZCIT, como os Vórtices Ciclônicos em Altos Níveis - VCAN, Distúrbios Ondulatórios de Leste - DOLs, Complexos Convectivos de Mesoescala, dentre outros.

\section{METODOLOGIA}

No intuito de fomentar as análises e discussões desenvolvidas, fez-se necessário um levantamento bibliográfico sobre a temática abordada, a partir de autores que explicam os desastres naturais/socionaturais em uma perspectiva teórica, inclusive aqueles mais recorrentes no Estado do Ceará (secas e inundações), além de autores que evidenciam e analisam os principais sistemas atmosféricos e teleconexões que podem oferecer uma influência significativa no comportamento da chuva.

Posteriormente, foram obtidos dados pluviométricos através da Fundação Cearense de Meteorologia e Recursos Hídricos FUNCEME, com a utilização de dados de precipitações do posto pluviométrico de Hidrolândia, o Posto 55, no intuito de analisar o comportamento da chuva no período 1989-2018.

No intuito de definir e classificar, de forma clara e objetiva, anos secos e chuvosos, após a tabulação das informações sobre os acumulados de chuva do posto, foi aplicada a técnica dos quantis, 
através do método que Pinkayan (1966) empregou em sua pesquisa, uma divisão em 5 classes: Muito Seco, Seco, Normal, Chuvoso e Muito Chuvoso, a partir da série histórica de 30 anos (1989 a 2018).

Tais classes foram representadas a partir do intervalo entre os quantis $\mathrm{Q}(0,15), \mathrm{Q}(0,35), \mathrm{Q}(0,65)$ e $\mathrm{Q}(0,85)$. As classes extremas (Muito Seco e Muito Chuvoso), neste sentido, apresentam um intervalo relativamente menor (apenas 15\%), o que permite uma abordagem estatística mais compreensível e correta que leva em consideração uma distribuição normal, uma vez que a classe Normal apresenta o maior intervalo (30\%).

Uma análise compreensível para o quantil Qp é a seguinte: acreditando que a probabilidade $\mathrm{p}$ é expressada em porcentagens, espera-se que em $\mathrm{p}(\%)$ dos anos a quantidade de chuva " $X$ " não deve extrapolar o valor desse quantil Qp, em milímetros, à medida que para $(100-p) \%$ dos anos tal valor será ultrapassado. A título de exemplo, para as ordens quantílicas $\mathrm{p}=0,15 ; 0,35 ; 0,65 ; \mathrm{e} 0,85$ $(15 \%, 35 \%, 65 \%$ e $85 \%)$, os quantis referentes são $\mathrm{Q}(0,15)$, $\mathrm{Q}(0,35), \mathrm{Q}(0,65)$ e $\mathrm{Q}(0,85)$. Dessa forma, possuiríamos uma divisão em 5 classes (MONTEIRO, 2011; XAVIER, 2001).

Desta forma, a totalidade de chuva armazenada em cada mês de cada ano da série histórica são colocados juntos em uma tabela e, logo depois, os valores são reunidos para obtenção do total pluviométrico acumulado durante cada ano. Em seguida, os valores anuais são ordenados, ou seja, do menor para o maior, com a finalidade de aplicar a técnica dos quantis.

$\mathrm{Na}$ intenção de simplificar a compreensão da distribuição normal dos quantis para os anos observados na série histórica, os acumulados foram dispostos do ano mais seco para o mais chuvoso da série, no intuito de compreender melhor, em sua essência, a aplicação da técnica (Figura 2).

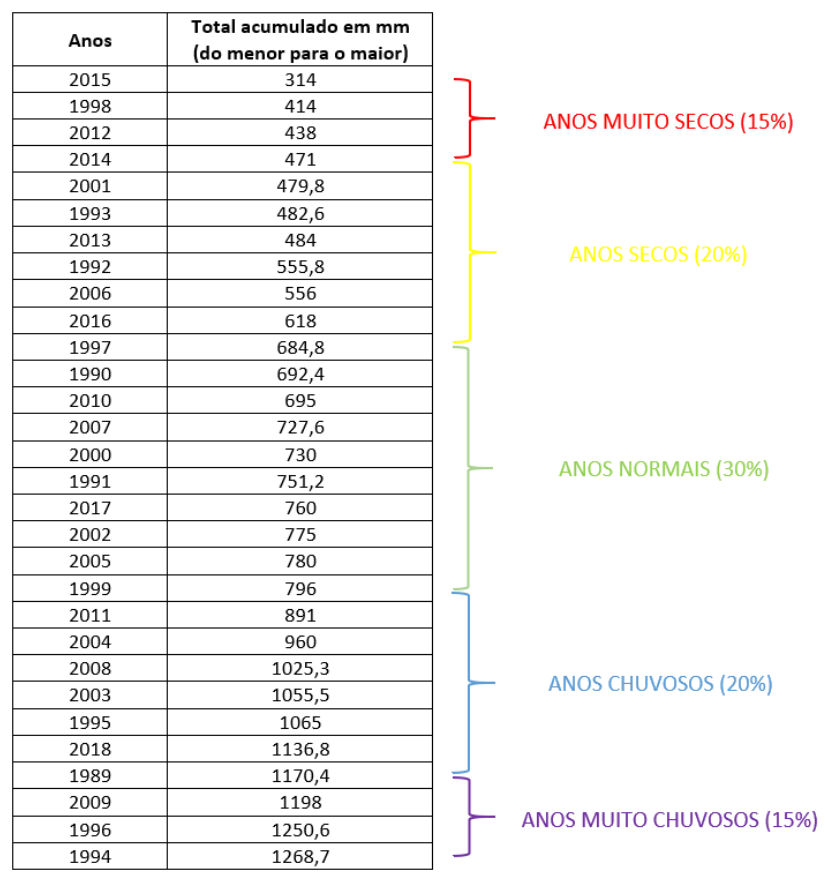

Figura 2 - Valores de chuva acumulada nos anos da série histórica e suas prováveis classificações conforme a divisão proposta na pesquisa. Fonte: adaptado de Monteiro (2011).
Foram realizadas consultas ao Sistema Integrado de Informações sobre Desastres (S2iD), a partir dos relatórios que apresentam os diversos danos e prejuízos ocasionados por situações de desastres nos anos mais chuvosos e mais secos em Hidrolândia (considerando o recorte temporal 1989-2018), bem como os arquivos digitais que contêm documentos que consolidam um histórico dos desastres associados a fenômenos adversos.

Cabe salientar que o Sistema Integrado de Informações sobre Desastres (S2iD) faz uma distinção entre os termos seca e estiagem. Considera seca, com base no conceito meteorológico, onde a seca seria uma estiagem prolongada, caracterizada por ocasionar uma redução drástica nos reservatórios hídricos existentes. Por sua vez, a estiagem é caracterizada por apresentar uma redução nas atividades pluviométricas, nesse caso, a ausência de chuva durante o determinado período chuvoso.

De forma concomitante, foram identificados e analisados os sistemas atmosféricos e teleconexões que exerceram importante influência no acumulado de chuva em Hidrolândia em cada ano do período de análise.

\section{RESULTADOS E DISCUSSÃO}

Em Hidrolândia, as chuvas se intensificam no quadrimestre chuvoso, ou seja, no período entre os meses de fevereiro e maio. Nos demais meses, geralmente observa-se a estação seca, principalmente no segundo semestre do ano.

Desta forma, os acumulados anuais da série histórica analisada durante os trinta anos (1989-2018), considerando o posto pluviométrico 55 (posto localizado na sede de Hidrolândia), foram colocados em ordem crescente (Figura 3) para posterior à aplicação da técnica dos quantis, definindo assim os quantis $\mathrm{Q}(0,15), \mathrm{Q}(0,35), \mathrm{Q}(0,50), \mathrm{Q}(65)$ e $\mathrm{Q}(0,85)$.

\begin{tabular}{|c|c|c|c|c|c|c|c|c|c|c||}
\hline $\mathbf{i}$ & 1 & 2 & 3 & 4 & 5 & 6 & 7 & 8 & 9 & 10 \\
\hline $\mathbf{y}(\mathbf{m m})$ & 314 & 414 & 438 & 471 & 479,8 & 482,6 & 484 & 555,8 & 556 & 618 \\
\hline \multirow{2}{*}{$\left.\mathbf{P}_{\mathbf{i}} \mathbf{i} / \mathbf{N}+1\right)$} & $1 / 31$ & $2 / 31$ & $3 / 31$ & $4 / 31$ & $5 / 31$ & $6 / 31$ & $7 / 31$ & $8 / 31$ & $9 / 31$ & $10 / 31$ \\
\cline { 2 - 12 } & 0.032 & 0.064 & 0.096 & 0.129 & 0.161 & 0.193 & 0.225 & 0.258 & 0.290 & 0.322 \\
\hline $\mathbf{i}$ & 11 & 12 & 13 & 14 & 15 & 16 & 17 & 18 & 19 & 20 \\
\hline $\mathbf{y}(\mathbf{m m})$ & 684,8 & 692,4 & 695 & 727,6 & 730 & 751,2 & 760 & 775 & 780 & 796 \\
\hline \multirow{2}{*}{$\left.\mathbf{P}_{\mathbf{i}} \mathbf{i} / \mathbf{N}+\mathbf{1}\right)$} & $11 / 31$ & $12 / 31$ & $13 / 31$ & $14 / 31$ & $15 / 31$ & $16 / 31$ & $17 / 31$ & $18 / 31$ & $19 / 31$ & $20 / 31$ \\
\cline { 2 - 12 } & 0.354 & 0.387 & 0.419 & 0.451 & 0.483 & 0.516 & 0.548 & 0.580 & 0.612 & 0.645 \\
\hline $\mathbf{i}$ & 21 & 22 & 23 & 24 & 25 & 26 & 27 & 28 & 29 & 30 \\
\hline $\mathbf{y}(\mathbf{m m})$ & 891 & 960 & 1025,3 & 1055,5 & 1065 & 1136,8 & 1170,4 & 1198 & 1250,6 & 1268,7 \\
\hline \multirow{2}{*}{$\mathbf{P}_{\mathbf{i}}=\mathbf{i} /(\mathbf{N}+1)$} & $21 / 31$ & $22 / 31$ & $23 / 31$ & $24 / 31$ & $25 / 31$ & $26 / 31$ & $27 / 31$ & $28 / 31$ & $29 / 31$ & $30 / 31$ \\
\cline { 2 - 10 } & 0.677 & 0.709 & 0.741 & 0.774 & 0.806 & 0.838 & 0.870 & 0.903 & 0.935 & 0.967 \\
\hline \hline
\end{tabular}

Figura 3 - Valores ordenados para aplicação da técnica dos quantis em Hidrolândia.. Fonte: adaptado de Monteiro (2011).

Após aplicação da técnica estatística dos quantis, foram identificados os limiares em milímetros ( $\mathrm{mm}$ ) previstos, determinando assim as cincos classes propostas (Figura 4). 


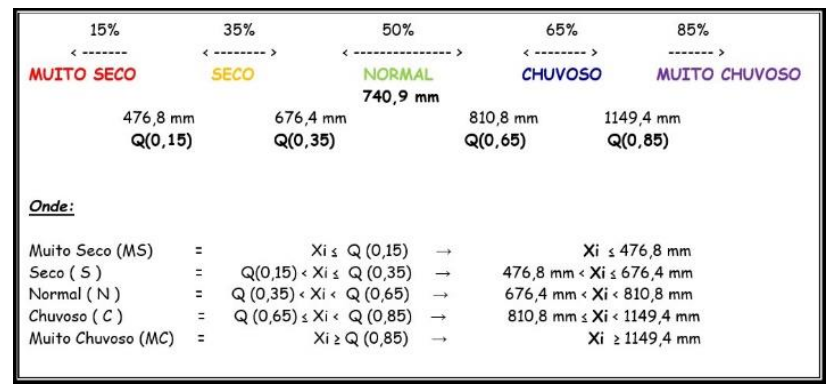

Figura 4 - Valores estabelecidos para os quantis de Hidrolândia. Fonte: adaptado de Monteiro (2011).

Assim, os acumulados anuais situados abaixo do limiar do $\mathrm{Q}(0,15)$ ficaram classificados como muito seco, enquanto que entre $\mathrm{Q}(0,15)$ e $\mathrm{Q}(0,35)$ na classe seco, entre $\mathrm{Q}(0,35)$ e $\mathrm{Q}(0,65)$ na classe normal, entre $\mathrm{Q}(0,65)$ e $\mathrm{Q}(0,85)$ na classe chuvoso, e os acumulados anuais acima de $\mathrm{Q}(0,85)$ na classe muito chuvoso.

Em seguida, os acumulados anuais, após sua devida classificação, foram organizados no intuito de facilitar a visualização (Tabela 1).
Tabela 1 - Classificação dos valores estabelecidos para cada classe quantílica da série histórica de Hidrolândia (1989-2018). Fonte: autor (2021). Fonte: autor (2021).

\begin{tabular}{|c|c|c|}
\hline Anos & $\begin{array}{c}\text { Acumulado } \\
\text { (em milímetros) }\end{array}$ & Classificação \\
\hline 1989 & 1170,4 & Muito Chuvoso \\
\hline 1990 & 692,4 & Normal \\
\hline 1991 & 751,2 & Normal \\
\hline 1992 & 555,8 & $\mathrm{Seco}$ \\
\hline 1993 & 482,6 & $\mathrm{Seco}$ \\
\hline 1994 & 1268,7 & Muito Chuvoso \\
\hline 1995 & 1065 & Chuvoso \\
\hline 1996 & 1250,6 & Muito Chuvoso \\
\hline 1997 & 684,8 & Normal \\
\hline 1998 & 414 & Muito Seco \\
\hline 1999 & 796 & Normal \\
\hline 2000 & 730 & Normal \\
\hline 2001 & 479,8 & Seco \\
\hline 2002 & 775 & Normal \\
\hline 2003 & 1055,5 & Chuvoso \\
\hline 2004 & 960 & Chuvoso \\
\hline 2005 & 780 & Normal \\
\hline 2006 & 556 & Seco \\
\hline 2007 & 727,6 & Normal \\
\hline 2008 & 1025,3 & Chuvoso \\
\hline 2009 & 1198 & Muito Chuvoso \\
\hline 2010 & 695 & Normal \\
\hline 2011 & 891 & Chuvoso \\
\hline 2012 & 438 & Muito Seco \\
\hline 2013 & 484 & Seco \\
\hline 2014 & 471 & Muito Seco \\
\hline 2015 & 314 & Muito Seco \\
\hline 2016 & 618 & \\
\hline 2017 & 760 & Normal \\
\hline 2018 & 1136,8 & Chuvoso \\
\hline
\end{tabular}

Com a finalidade de identificar a ocorrência de desastres socionaturais em Hidrolândia, foram utilizadas informações da Defesa Civil do Estado, através do banco de dados do Sistema Integrado de Informações sobre Desastres (S2iD), que contêm documentos que apontam para a ocorrência de possíveis situações de desastre. Estes apresentam informações sobre número de atingidos e decretos de Situação de Emergência (SE) e Estado de Calamidade Pública (ECP), os quais são importantes indicadores de situações de desastre associados à seca, estiagem e inundações (Tabela 2). 
Tabela 2 - Histórico dos desastres associados: secas, estiagens e inundações em Hidrolândia. Fonte: Sistema Integrado de Informações sobre Desastres $(S 2 i D)$.

\begin{tabular}{c|c|c|c|c}
\multicolumn{5}{c}{ Histórico dos desastres associados: secas, estiagens e } \\
inundaços - Hidrolândia \\
\hline Ano & Documento & Evento & $\begin{array}{c}\text { Tipo de } \\
\text { Decreto }\end{array}$ & $\begin{array}{c}\text { Números } \\
\text { de } \\
\text { Atingidos }\end{array}$ \\
\hline 1993 & Portaria & Seca & ECP & - \\
\hline 2001 & Portaria & Estiagem & ECP & - \\
\hline 2005 & Avadan & Estiagem & SE & 8565 \\
\hline 2007 & Avadan & Estiagem & SE & 8843 \\
\hline 2008 & Avadan & Inundações & - & 18116 \\
\hline 2009 & Avadan & Inundações & SE & 3302 \\
\hline 2010 & Avadan & Estiagem & SE & 5156 \\
\hline 2012 & Nopred & Estiagem & SE & 4660 \\
\hline 2013 & Portaria & Seca & SE & - \\
\hline 2014 & Fide & Seca & SE & 572 \\
\hline 2015 & Fide & Seca & SE & 572 \\
\hline 2016 & Fide & Seca & - & 5720 \\
\hline
\end{tabular}

Contudo, cabe salientar que os anos iniciais da série histórica analisada não apresentavam informações suficientes quanto ao número de atingidos, por exemplo. Apenas obteve-se acesso às portarias que reconheciam situações de seca e estiagem, bem como possíveis decretos de Situação de Emergência - SE e Estado de Calamidade Pública - ECP emitidos pelo Governo do Estado do Ceará.

Hidrolândia apresentou, considerando a série histórica em análise, um maior número de decretos de situação de emergência (SE), os quais ocorreram em oito anos (2005, 2007, 2009, 2010, 2012, 2013, 2014, 2015). Nestes anos, os desastres associados à estiagem e seca foram mais recorrentes. Dentre eles, anos consecutivos (2014 e 2015), foram considerados anos muito secos.

Inclusive, no ano de 2015 foi identificado o menor acumulado pluviométrico na série histórica analisada e, como resultado, verificou-se uma perda na produção agrícola, acarretando na venda de rebanho de bovinos, ovinos, caprinos e dentre outros animais e produtos da pecuária.

Registrou-se, sobretudo, a redução drástica do aporte hídrico do açude Paulo Sarasate (Araras), chegando a um nível alarmante, com cerca de $3,46 \%$ de sua capacidade (Figura 5), culminando em problemas de abastecimento no município. No entanto, Decretos de Estado de Calamidade Pública (ECP), ocorreram apenas em dois anos (1993 e 2001). Os mesmos foram apontados como anos secos da série histórica. (a)

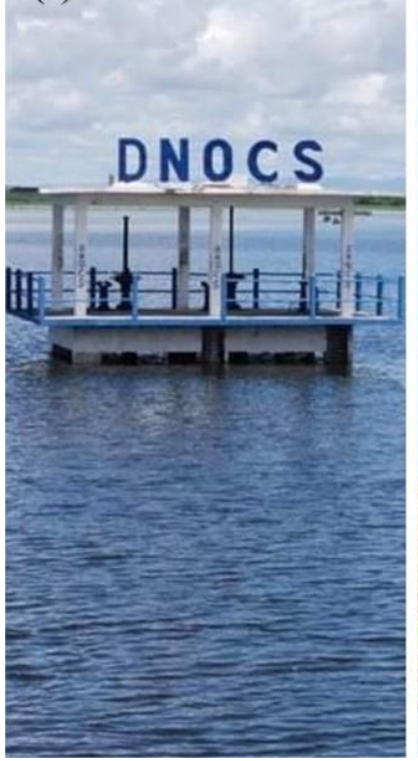

Figura 5 - Comparação do aporte hídrico do açude Paulo Sarasate (Araras): quantidade máxima atingida em 2009 (a) e quantidade mínima atingida em 2015 (b). Fonte: Portal Hidrolândia 24 horas $(2015$.

Considerando as inundações, observou-se Decreto de Situação de Emergência (SE) apenas no ano de 2009, considerado muito chuvoso em Hidrolândia, apresentando um dos maiores acumulados registrados na série histórica trabalhada, aproximadamente $1198,0 \mathrm{~mm}$. O elevado aporte hídrico do riacho Batoque, por exemplo, ocasionou inundações na sede urbana de Hidrolândia, especificamente nos bairros Progresso, Nova Hidrolândia e Vila Freitas (Figura 6).

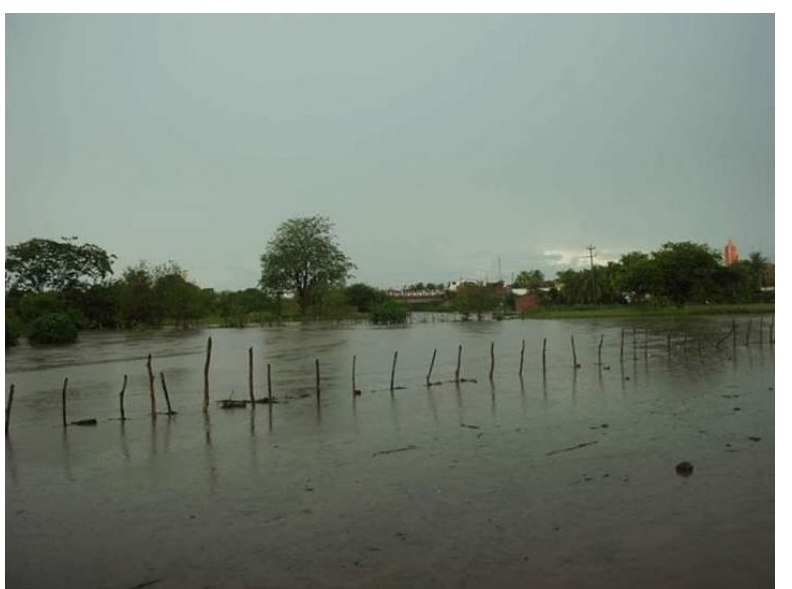

Figura 6 - Ocorrência de inundação na sede urbana de Hidrolândia no ano de 2009. Fonte: Portal Hidrolândia 24 horas (2011). 
O ano de 2008 também apresentou um importante acumulado $(1025,3 \mathrm{~mm})$ e destaca-se pelo número de atingidos por inundações (mais de 18.000 atingidos, de acordo com as informações da Defesa Civil).

Os documentos disponibilizados no S2iD chamam atenção pelos prejuízos mencionados, como sangria e arrombamentos de açudes, danos a estradas e comprometimento de serviços básicos (como saúde e educação), afetando diretamente as famílias da zona rural de Hidrolândia, sobretudo os distritos Betânia e Conceição.

Quanto aos prejuízos econômicos, a agricultura de subsistência foi a mais afetada. Culturas de milho e feijão apresentaram prejuízos significativos. Neste período, era esperada uma produção inicial de 10935 toneladas, por conta das chuvas intensas. Porém, observou-se uma produção final com cerca de 6665 toneladas, obtendo uma perda média de $39,14 \%$ da lavoura prevista para colheita. Em consequência, a renda de muitas famílias foi impactada.

Quanto ao número de pessoas atingidas pelos desastres socionaturais ocorridos em Hidrolândia, estes foram mais expressivos quando associados às estiagens, conjuntamente com as secas.

De acordo com os dados da Defesa Civil, os anos de 2014, 2015 e 2016 foram notificados através do Formulário de Informações de Desastres - FIDE. O formulário é utilizado para designar o reconhecimento das Situações de Emergência (SE) ou de Estado de Calamidade Pública (ECP) referente aos desastres.

Nestes anos, a população mais afetada foi aquela residente na zona rural, principalmente dos distritos de Irajá, Betânia e Conceição. Em decorrência da situação de seca, verificou-se uma perda significativa na produção agrícola, como também na atividade pecuária, inclusive com a diminuição no aporte hídrico do reservatório Paulo Sarasate (Araras) que abastece o município (Figura 7).

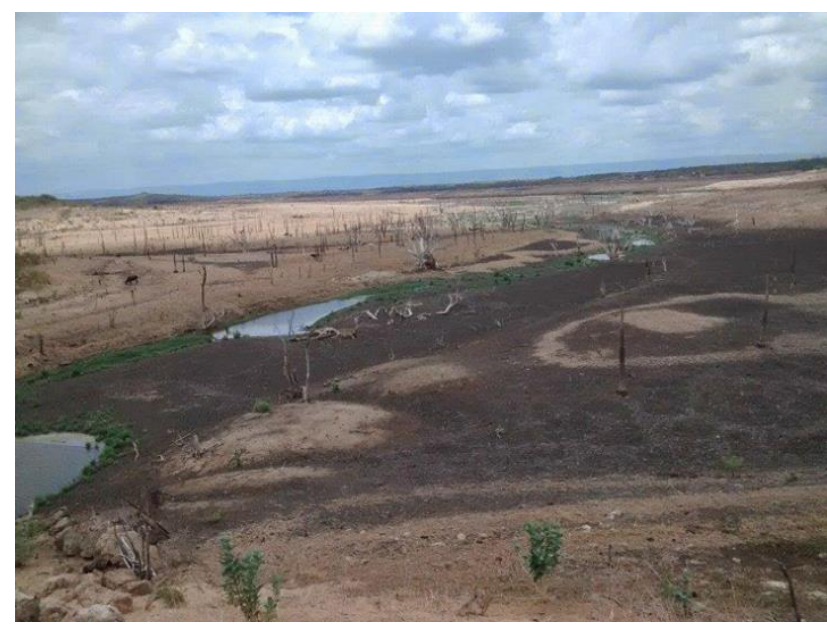

Figura 7 - Escassez hídrica do reservatório Paulo Sarasate (Araras) no ano de 2015. Fonte: Paiva (2015).

Vale ressaltar que dezoito anos da série histórica em análise (1989, 1990, 1991, 1992, 1994, 1995, 1996, 1997, 1998, 1999, 2000, 2002, 2003, 2004, 2006, 2011, 2017 e 2018) sequer foram mencionados aqui. Isso não significa que situações de desastre não foram experenciadas pela população. Acredita-se que alguns danos não foram devidamente registrados/identificados no Sistema ou não foram notificados pelo município/Defesa Civil, podendo acarretar em uma deficiência de informações.

Com relação a influência de sistemas atmosféricos nos anos da série histórica analisada, a Zona de Convergência Intertropical - ZCIT foi o sistema atmosférico que mais influenciou no acumulado de chuvas durante o quadrimestre chuvoso (fevereiro, março, abril e maio). Este é considerado um sistema de ampla proporção, formado através do encontro dos ventos alísios do hemisfério norte e do hemisfério sul, onde as Temperaturas da Superfície do Mar (TSM) é uma das condições determinantes para o seu posicionamento e, sobretudo, sua intensidade.

Quanto às teleconexões oceano-atmosfera, observa-se uma importante influência do El Niño em anos secos, que nada mais é que o aquecimento das temperaturas da superfície marítima no Oceano Pacífico Equatorial, interferindo na formação de nuvens de chuva no quadrimestre chuvoso e desencadeando menores acumulados no Estado e, consequentemente, em Hidrolândia. Por sua vez, o fenômeno oposto, denominado de "La Niña", em referência ao resfriamento das águas do Pacífico Equatorial, pode ter contribuído para acumulados expressivos no quadrimestre chuvoso, situação verificada em 1989, 2008 e 2009, por exemplo.

O El Niño atuou no período analisado, variando entre fraco (no ano de 2015), em transição de neutro para fraco nos anos 1991, 1997 e 2002, moderado em apenas um ano (1992) e forte nos anos 1998 e 2016 (Tabela 3). Já a La Niña variou de fraca em três anos (2009, 2017 e 2018), moderada em dois anos (2008 e 2011) e forte nos anos 1989 e 2010. Além disso, observaram-se anos considerados neutros: 1990, 1993, 1994, 2004, 2013 e 2014.

Tabela 3 - ENOS e Dipolo do Atlântico no quadrimestre fevereiro-maio. Fonte: Autor (2021), baseado em informações da FUNCEME \& NOAA.

\begin{tabular}{|c|c|c|}
\hline \multicolumn{3}{|c|}{$\begin{array}{c}\text { ENOS e Dipolo do Atlântico no quadrimestre fevereiro- } \\
\text { maio }\end{array}$} \\
\hline Ano & $\begin{array}{c}\text { Enos no Quadrimestre } \\
\text { Fevereiro-Maio }\end{array}$ & Dipolo do Atlântico \\
\hline 1989 & La Niña Forte & Favorável (negativo) \\
\hline 1990 & Neutro & Neutro \\
\hline 1991 & $\begin{array}{c}\text { Transição Neutro/El } \\
\text { Niño Fraco }\end{array}$ & Favorável (negativo) \\
\hline 1992 & El Niño Moderado & Desfavorável (positivo) \\
\hline 1993 & Neutro & Neutro \\
\hline 1994 & Neutro & Favorável (negativo) \\
\hline 1995 & $\begin{array}{l}\text { Transição El Niño } \\
\text { Fraco/Neutro }\end{array}$ & Favorável (negativo) \\
\hline 1996 & $\begin{array}{c}\text { Transição La Niña } \\
\text { Fraca/Neutro } \\
\end{array}$ & Favorável (negativo) \\
\hline 1997 & $\begin{array}{c}\text { Transição Neutro/El } \\
\text { Niño Fraco }\end{array}$ & Desfavorável (positivo) \\
\hline 1998 & El Niño Forte & Neutro \\
\hline 1999 & La Niña Moderada & Favorável (negativo) \\
\hline 2000 & La Niña Moderada & Favorável (negativo) \\
\hline
\end{tabular}




\begin{tabular}{|c|c|c|}
\hline 2001 & $\begin{array}{l}\text { Transição La Niña } \\
\text { Fraca/Neutro }\end{array}$ & Neutro \\
\hline 2002 & $\begin{array}{c}\text { Transição Neutro/El } \\
\text { Niño Fraco }\end{array}$ & Favorável (negativo) \\
\hline 2003 & $\begin{array}{l}\text { Transição El Niño } \\
\text { Fraco/Neutro }\end{array}$ & Neutro \\
\hline 2004 & Neutro & Neutro \\
\hline 2005 & $\begin{array}{l}\text { Transição El Niño } \\
\text { Fraco/Neutro }\end{array}$ & Desfavorável (positivo) \\
\hline 2006 & $\begin{array}{l}\text { Transição La Niña } \\
\text { Fraca/Neutro }\end{array}$ & Neutro \\
\hline 2007 & $\begin{array}{l}\text { Transição El Niño } \\
\text { Fraco/Neutro }\end{array}$ & Desfavorável (positivo) \\
\hline 2008 & La Niña Moderada & Favorável (negativo) \\
\hline 2009 & La Niña Fraca & Favorável (negativo) \\
\hline 2010 & La Niña Forte & Neutro \\
\hline 2011 & La Niña Moderada & Favorável (negativo) \\
\hline 2012 & $\begin{array}{c}\text { Transição La Niña } \\
\text { Fraca/Neutro } \\
\end{array}$ & Desfavorável (positivo) \\
\hline 2013 & Neutro & Neutro \\
\hline 2014 & Neutro & Favorável (negativo) \\
\hline 2015 & El Niño Fraco & Desfavorável (positivo) \\
\hline 2016 & El Niño Forte & Favorável (negativo) \\
\hline 2017 & La Niña Fraca & Favorável (negativo) \\
\hline 2018 & La Niña Fraca & Desfavorável (positivo) \\
\hline
\end{tabular}

parece oferecer à região uma importante predição de que mais um ano de 'seca' será experenciado. Ademais, temperaturas mais aquecidas distantes da costa, em porções setentrionais do Oceano Atlântico Intertropical acabam por interferer no posicionamento da ZCIT, não trazendo umidade suficiente no quadrimestre chuvoso tão aguardado pela população desse ambiente semiárido.

A aplicação da técnica dos quantis demonstrou para o município de Hidrolândia, de forma clara e objetiva, uma relevância metodológica e sistemática para o estudo climático na determinação de períodos secos e chuvosos em uma longa série histórica. Ademais, contribuiu para a análise de possíveis influências (teleconexões oceano-atmosfera e sistemas atmosféricos) que interferiram no comportamento da chuva na localidade.

Por fim, procurar entender o comportamento da chuva em Hidrolândia representa um primeiro passo para aprender a lidar com situações de desastre socionatural, possibilitando aos tomadores de decisão recursos para 'pensar' e desenvolver medidas mitigadoras, minimizando impactos e estabelecendo uma cultura de convivência.

No entanto, tais medidas fazem parte de um sistema bastante melindroso, envolvendo vários atores sociais, responsabilidades e mudança de atitude. Ou seja, mais do que compreender a chuva e a exposição à riscos associados à inundações e secas, faz-se necessário analisar a vulnerabilidade das populações, a resiliência, entre outros componentes que configuram essa complexa equação.

\section{REFERÊNCIAS}

ALVES, Joaquim. História das secas: séculos XVII a XIX. Fortaleza: Fundação Waldemar Alcântara, 2003. 262 p.

Nos últimos anos, os impactos resultantes dos desastres socionaturais relacionados às precipitações (acumulados superiores e inferiores) tem-se intensificado no Brasil. No que se refere ao Estado do Ceará, a cidade de Hidrolândia apresentou alguns fenômenos de estiagens, secas e inundações que durante o período em análise contribuíram para o desencadeamento de prejuízos econômicos e materiais, impactando diretamente a sociedade e que foram caracterizados como Desastres Socionaturais.

Em conformidade com os resultados levantados a partir desta investigação, foi possível constatar a importante influência que a atuação da Zona de Convergência Intertropical - ZCIT exerce para a obtenção de acumulados expressivos em anos chuvosos. Do contrário, a estiagem/seca acaba apresentando-se como o desastre que desencadeia danos significativos naquele respectivo ano em análise.

Em anos de "La Niña", o cenário geralmente aponta para um posicionamento favorável da ZCIT. No entanto, há que se observar também o papel importante das TSMs do Atlântico Tropical que, quando encontram-se mais aquecidas próxima à costa do Nordeste e resfriadas em porções mais setentrionais do Atlântico, apresentam condições favoráveis à intensificação/atuação da ZCIT. No entanto, esse padrão cambiante pode modificar o cenário esperado rapidamente.

Quanto aos períodos secos, a ocorrência do El Niño, principalmente se este for de forte ou moderada intensidade,

CEPED/ UFSC. Universidade Federal de Santa Catarina. Centro Universitário de Estudos e Pesquisas sobre Desastres. Atlas brasileiro de desastres naturais 1991 a 2010: volume Brasil. Florianópolis: CEPED/UFSC, 2012. 94p.

FERREIRA, Antônio Geraldo; MELLO, Namir Giovanni da Silva. Principais sistemas atmosféricos atuantes sobre a Região Nordeste do Brasil e a influência dos Oceanos Pacífico e Atlântico no clima da região. Revista Brasileira de Climatologia, Presidente Prudente, v. 1, n. 1, p. 15-28, 2005.

KOBIYAMA, Masato; MENDONÇA, Magaly; MORENO, Davis Anderson; MARCELINO, Isabela P. V. de Oliveira; MARCELINO, Emerson V.; GONÇALVES, Edson F.; BRAZETTI, Letícia Luiza Penteado; GOERL, Roberto Frabris; MOLLERI, Gustavo S. Fontes; RUDORFF, Federico de Moraes. Prevenção de desastres naturais: conceitos básicos. Curitiba - PR: Organic Trading, 2006. $109 \mathrm{p}$.

MAFFRA, Cristina de Queiroz Telles; MAZOLLA, Marcelo. As razões dos desastres em território brasileiro. In: SANTOS, Rozely Ferreira dos (Org.). Vulnerabilidade ambiental: desastres naturais ou fenômenos induzidos? Brasília: MMA, 2007. p. 9-12. 
MONTEIRO, J. B. Chover, mas chover de mansinho: desastres naturais e chuvas extremas no Estado do Ceará. 2011. Dissertação (Mestrado em Geografia.) - Programa de Pósgraduação em Geografia, Centro de Ciência e Tecnologia da Universidade Estadual do Ceará. Fortaleza, 2011. 198 p.

MONTEIRO, J. B. Desastres naturais no estado do Ceará: uma análise de espisódios pluviométricos extremos. 2016. Tese (Doutorado em Geografia) - Centro de Ciências, Departamento de Geografia, Universidade Federal do Ceará. Fortaleza, 2016. 255 p.

MONTEIRO, J. B. ZANELLA, M. E. Desnaturalizando o desastre: as diferentes concepções teóricas que envolvem o conceito de desastre natural. Revista da Casa da Geografia de Sobral, Sobral; v. 21, n. 1, p. 40-54, Jun. 2019. Disponível em: <http://uvanet.br/rcgs>. Acesso em: 30 de jul. de 2019.
PINKAYAN, S. Conditional probabilities of ocurrence of Wet and Dry Years Over a Large Continental Area. Colorado: Hidrology Papers/State University, 1966.

ROMERO, Gilberto; MASKREY, Andrew. Como entender los desastres naturales. Predes, 1993, n.1, 5 p.

SOUZA, M. J. N. Compartimentação Geoambiental do Ceará. In: SILVA, J. B.; CAVALCANTE, T. C.; DANTAS, E. W. C. Ceará: um novo olhar geográfico. Fortaleza: Edições Demócrito Rocha, 2007. p.127-140.

TOBIN, G. A; MONTZ, B. E. Natural hazards: explanation and integration. New York: The Guilford Press, 1997. 388p.

XAVIER, Terezinha de Maria Bezerra S. Tempo de chuva: estudos climáticos e de previsão para o Ceará e Nordeste setentrional. Fortaleza: ABC Editora, 2001.

Recebido em: 30/04/2020

Aceito para publicação em: 30/09/2021 